\title{
Monitoramento e controle de larvas de Culicidae em criadouros artificiais na área da Usina Hidrelétrica de Dona Francisca, Agudo, Rio Grande do Sul
}

Carolina Coelho Sokolowicz

Luciane Ayres Peres

SANDRO SANTOS

\section{Resumo}

O objetivo desse trabalho foi realizar um monitoramento e controle das larvas de Culicidae na área da Usina Hidrelétrica de Dona Francisca (UHDF), Agudo, RS. Havia uma grande preocupação de se evitar a introdução de mosquitos vetores de doenças humanas nesta localidade, durante a construção da usina. Foram determinados seis pontos estratégicos na vila da UHDF, ao lado do canteiro de obras, onde foram realizadas as inspeções e capturas de larvas, trimestralmente, de junho/2000 a fevereiro/2001 (piscinas do hotel, clube dos funcionários, estação de tratamento de água, quadra administrativa, alojamento dos trabalhadores e borracharia). Além do monitoramento de larvas, foram proferidas palestras para cerca de três mil pessoas, em escolas próximas à UHDF. Durante o estudo não foram encontrados vetores da dengue e febre amarela, somente larvas de Culex, Limatus, Orthopodomyia e Aedes fluviatilis. O número de criadouros e de mosquitos amostrados foi decrescente durante o período. A correlação entre o número de larvas e os fatores ambientais (temperatura, precipitação e umidade relativa do ar) não foi significativa, provavelmente em função do controle e redução dos criadouros artificiais.

Palavras- Chave: Culicidae, Monitoramento, Usina Hidrelétrica de Dona Francisca 


\section{Summary}

The aim of this work was to monitory and control of the immature mosquitoes around Dona Francisca Hydroelectric (DFH), Agudo, RS. There was a great concern to avoid the introducing of human diseases vectors in this place. Six areas were selected for sampling larva: The hotel swimming pool, the clubhouse near Jacui river, the station of water treatment, the administration square, workers lodgings and tyre fixing places. The collections were taken at three months intervals, during the building period of DFH (June/2000 to February/2001). Lectures were provided for about three thousand people in schools near DFH. No important epidemic species was found, only Aedes fluviatilis and other species of genus Culex, Limatus, and Orthopodomyia. The numbers of artificial breeding places and captured immature mosquitoes decreased throughout the study. There was not significant correlation between the number of mosquitoes captured and the environment factors (temperature, precipitation, and air relative humidity) probably due to the control and decreasing in artificial breeding places.

Key words: Culicidae, Mosquitoes, Monitory, Dona Francisca Hydreletric

\section{Introdução}

A ação humana em áreas antes preservadas pode favorecer o aparecimento de espécies de mosquitos que têm plasticidade genética para viver em criadouros artificiais que se formam em objetos descartados pelo homem, como pneus, latas e tonéis. O convivio humano com esses animais pode possibilitar o aparecimento de zoonoses (LOPES, 1997).

Os locais de desenvolvimento mais comuns de mosquitos são coleções superficiais de precipitações atmosféricas, pântanos e alagadiços de água doce ou salobra, e mesmo pegadas de animais, cavidades em rochas, buracos de árvores, bromeliáceas e recipientes artificiais, esses criadouros são denominados transitórios (FORATTINI, 1965). Em geral, as larvas de mosquitos do gênero Culex se desenvolvem em águas poluídas, ricas em matéria orgânica e em fermentação (FORATTINI, op.cit.). Já os criadouros de Aedes são caracteristicamente transitórios, e suas larvas podem se desenvolver em pneus, copos plásticos, caixas d'água e outros ambientes com deposição de água (FORATTINI, 1965).

Com a construção da Usina Hidrelétrica de Dona Francisca 
(UHDF), o fluxo de veículos e pessoas, provenientes de vários locais do pais, aumentou na região de Agudo (RS). Este fato, associado à capacidade que os culicídeos têm de se desenvolver em criadouros artificiais, poderia contribuir para a introdução de espécies que antes não ocorriam na região, incluindo vetores como Aedes aegyptie Aedes albopictus, agentes que podem transmitir a dengue e a febre amarela.

Fatores ambientais tais como temperatura, luminosidade, quantidade de matéria orgânica e pluviosidade podem interferir no tempo de desenvolvimento e na quantidade de larvas de mosquitos em uma área (CONSOLI \& OLIVEIRA, 1998). O tempo de desenvolvimento aumenta quando a temperatura diminui e é mais curto quando a mesma se eleva (FORATTINI, 1962). O objetivo desse trabalho foi realizar o monitoramento de larvas de culicídeos na UHDF para evitar a instalação de vetores (Aedes aegyptie Aedes albopictus), correlacionar a presença de larvas de mosquitos com os fatores ambientais, tais como: precipitação, umidade relativa e temperatura do ar, além de buscar conscientizar a população local e os trabalhadores, através de palestras e distribuição de material informativo, para que estes evitassem o descarte inadequado de objetos que pudessem servir de criadouros para os mosquitos.

\section{Material e métodos}

Antes do início do monitoramento das larvas na área da UHDF, foi feito um levantamento preliminar dos culicídeos que ocorriam nas cidades próximas à usina (Agudo, Faxinal do Soturno e Nova Palma) e também na vila da usina para detectar larvas dos vetores Aedes aegypti e Aedes albopictus, esse levantamento foi feito com a colaboração da Fundação Nacional de Saúde (FNS).

Neste levantamento todas as casas, terrenos, estabelecimentos comerciais e cemitérios, das cidades e da vila, foram visitados pelos técnicos da FNS ao menos uma vez, de dezembro/1998 a março/1999.

O período de monitoramento deste estudo compreendeu a fase em que foi registrado o maior número de pessoas e empresas trabalhando no canteiro de obras, ou seja, nos meses que antecederam o fechamento da barragem, que ocorreu em novembro/2000. Foram realizadas amostragens em junho, setembro e dezembro de 2000 e fevereiro de 2001. A usina foi inaugurada em março/2001.

Os pontos escolhidos para serem monitorados em todas 
as coletas na UHDF foram: 1) o clube da vila, 2) a estação de tratamento de água, 3) a borracharia, 4) a quadra administrativa da usina (com posto de combustivel, oficinas, marcenaria e escritórios), 5) os alojamentos dos trabalhadores e 6) o hotel (piscinas e arredores). Estes locais foram determinados junto com os técnicos da Fundação Nacional de Saúde, por serem aqueles mais propícios a instalação de larvas de mosquitos.

Em todos os pontos estratégicos foram vistoriados todos os recipientes onde as larvas de mosquitos pudessem se desenvolver, como latas, copos plásticos, pneus, tonéis, poças d’água, ou qualquer outro recipiente com capacidade de reter água. Cada criadouro encontrado foi considerado uma amostra.

As larvas encontradas foram retiradas dos criadouros com conchas e pipetas, e então colocadas em recipientes plásticos etiquetados contendo álcool $70 \%$ e transportadas para o Laboratório, no Departamento de Biologia (UFSM). No laboratório as larvas foram identificadas ao nível de gênero e, quando possivel, até espécie, com auxílio de chaves específicas (CONSOLI \& OLIVEIRA, 1998 e DARSIE, 1985).

A presença de larvas, em cada mês de amostragem, foi correlacionada com os fatores ambientais: precipitação, umidade relativa e temperatura do ar, através do teste de Correlação Linear de Pearson. Os dados ambientais foram obtidos junto à Estação Meteorológica da Universidade Federal de Santa Maria.

Além do trabalho de monitoramento, foram realizadas campanhas de conscientização junto à população local e empresas envolvidas com a obra, visando a eliminação de criadouros. Estas campanhas consistiram de palestras e distribuição de folhetos informativos em escolas e centros comunitários. As palestras foram dirigidas à população local, funcionários das obras e para escolas das cidades de Agudo, Arroio do Tigre, Estrela Velha, Ibarama, Nova Palma e Pinhal Grande. Nas palestras foram enfatizados aspectos da biologia e ecologia de espécies de mosquitos, as doenças transmitidas por elas e também a importância de não se descartar recipientes onde as larvas pudessem se desenvolver.

\section{Resultados}

Foram capturadas 889 larvas de Culicidae, distribuídas em 4 gêneros, Culex, Limatus, Orthopodomyia e Aedes, com predomí- 
nio de Culex (737 larvas), encontrado em todos os pontos e em todas as coletas, com exceção da última (Fevereiro/2001). O gênero Limatus foi representado por 57 indivíduos e foi encontrado somente na primeira coleta (Junho/2000), no clube. Foram coletadas 3 larvas de Orthopodomyia na última amostragem (Fevereiro/2001). O gênero Aedes foi representado por 92 larvas de $A$. fluviatilis encontradas nas 2 últimas coletas (Dezembro/2000 e Fevereiro/2001), na borracharia e na quadra administrativa.

Nenhuma das espécies de mosquito amostrada é vetora da dengue ou da febre amarela.

O número de larvas coletadas decresceu ao longo da realização do trabalho (Figura 1), assim como o número de criadouros encontrados; com exceção do mês de dezembro, quando houve um aumento do número de pneus com larvas encontrados na borracharia. $\mathrm{Na}$ última coleta (Fevereiro/2001) foram encontrados apenas dois criadouros com larvas na quadra administrativa.

O local onde registrou-se o maior número de indivíduos foi a borracharia (351 larvas), seguida pela quadra administrativa (334), clube (140) e alojamento (60). Na piscina do hotel foram encontradas apenas 4 larvas de Culex em dezembro. O único ponto amostrado no qual não foram encontradas larvas de mosquito foi na estação de tratamento de água.

Não houve correlação entre os fatores abióticos (temperatura, precipitação e umidade relativa do ar) com o número de indivíduos coletados (Tabelas I e II).

As palestras foram realizadas para alunos de 34 escolas das cidades próximas à área de construção da usina, e contaram com a presença de professores, pais e alunos.

\section{Discussão}

Havia uma grande preocupação que mosquitos vetores de doenças, como a dengue e a febre amarela (Aedes aegypti e Aedes albopictus), fossem introduzidos na área da UHDF durante a etapa de engenharia da construção. Isto porque nesta etapa o fluxo de pessoas e veículos, provenientes de várias partes do país, inclusive de regiões com incidência desses mosquitos, seria muito grande naquele local. Esse fato não se confirmou.

O gênero Culex (C. pipens fatigans) pode ser transmissor da filariose humana (FORATTINI, 1965), apesar disso o aparecimento dessas larvas não representa preocupação para os moradores 
locais, pois a doença nunca foi registrada na região de estudo; ou seja, não há o agente dessa doença na região. De qualquer maneira, durante o trabalho de construção da UHDF, foi realizado um acompanhamento, junto aos hospitais e casas de saúde da região, para se detectar a presença de pessoas com doenças transmitidas por mosquitos.

Não houve correlação entre os fatores ambientais analisados e o número de larvas, provavelmente devido à diminuição gradativa dos criadouros; no entanto, isso não significa que esses fatores não possam influenciar o desenvolvimento das larvas. Os coeficientes de correlação são sensíveis as mudanças aditivas e proporcionais entre as amostras; e são também afetados pelo tamanho dessas amostras (COELHO, 2000). Para que a correlação fosse positiva o número de criadouros analisados teria que ser constante. Observações feitas durante o desenvolvimento desse trabalho sugerem que a pluviosidade influi de maneira que se a quantidade de água no criadouro for muito elevada, a oviposição e o desenvolvimento dos ovos e das larvas podem ser prejudicados.

O controle das larvas de mosquitos, realizado através de campanha para a redução dos criadouros, pode ser considerado satisfatório, uma vez que o número de locais onde os mosquitos pudessem se desenvolver decresceu ao longo do desenvolvimento do trabalho. Como conseqüência houve uma diminuição no número de larvas registradas. Esse declínio sugere que a população assimilou a campanha de prevenção e se conscientizou da importância de diminuir a quantidade de criadouros e assim evitou o aparecimento de mosquitos vetores.

A ausência de larvas de Aedes aegypti e Aedes albopictus, na área da UHDF, não significa que o risco desses animais serem introduzidos na região esteja descartado, uma vez que o fluxo de pessoas e veículos agora é menor, porém não insignificante. Com o enchimento do reservatório, que deu origem ao lago que abastece a usina, há a possibilidade de aparecerem outros vetores, como Anopheles (vetor da malária) que pode se desenvolver em rios e lagos (CONSOLI \& OLIVEIRA, 1998). Além disso, com o fim das obras inicia-se o trabalho de demolição das casas da vila, onde será implantado um Parque Estadual, sendo que este trabalho de demolição precisa ser acompanhado, uma vez que é grande a probabilidade de recipientes com água parada serem deixados nesses locais. O monitoramento de Culicidae na região da UHDF continuará até março/2005. 


\section{Agradecimentos}

Ao grupo Dona Francisca Energética S.A. (DFESA), pelo financiamento do projeto e à Fundação Nacional de Saúde (regional de Santa Maria - RS) pela colaboração nas coletas e identificação dos animais.

\section{Referências bibliográficas}

COELHO, R.M.P. Fundamentos em Ecologia, ArtMed Editora, Porto Alegre, 247 p, 2000.

CONSOLI, R.A.G.B. \& OLIVEIRA, R.L. de. Principais Mosquitos de Importância Sanitária no Brasil, Editora FIOCRUZ 225 p, 1998

DARSIE, R. F. Jr. Mosquitoes of Argentina. Part I, Keys for Identification of Adult Females and Fourth Stage Larvae in English and Spanish (Diptera, Culicidae). Mosquito Systematics vol. 17 (3): 237-357, 1985.

FORATTINI, O.P. Entomologia Médica. Volume 1, Faculdade de Higiene e Saúde Pública, São Paulo, 662 p, 1962.

FORATTINI, O.P. Entomologia Médica. Volume 2, Universidade de São Paulo, 506 p, 1965.

LOPES, J. Ecologia de Mosquitos (Diptera, Culicidae) em Criadouros Naturais e Artificiais de Área Rural no Norte do Estado do Paraná, Brasil. VI. Coletas de Larvas no Peridomicílio. Revta. bras. Zool. 14 (3): 571-578, 1997. 


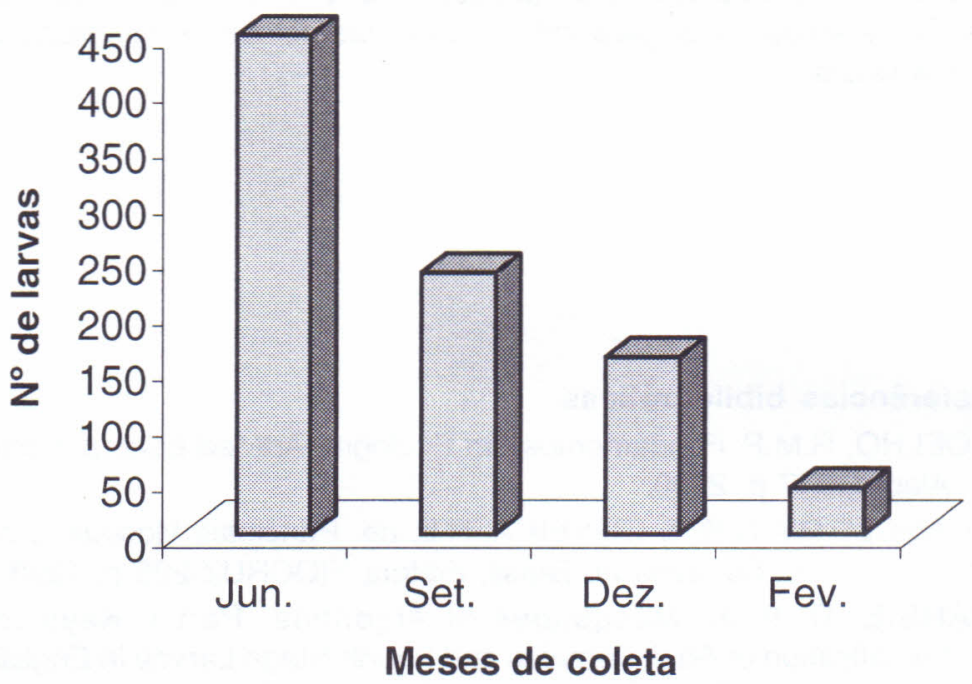

Fig. 1 - Número de larvas de Culicidae coletadas durante o período de estudo na Usina Hidrelétrica de Dona Francisca, Agudo (RS) 
Tabela I - Precipitação média do mês, temperatura do ar do mês, temperatura média do ar da quinzena, umidade relativa média do ar e número de amostras durante os meses de trabalho na UHDF

\begin{tabular}{cccccc}
\hline Mês & $\begin{array}{c}\text { Precipitação média } \\
\text { do mês }(\mathrm{mm})\end{array}$ & $\begin{array}{c}\text { Temperatura } \\
\text { média do } \\
\text { ar/mês }\left({ }^{\circ} \mathrm{C}\right)\end{array}$ & $\begin{array}{c}\text { Temperatura } \\
\text { média do } \\
\text { ar/quinzena }\left({ }^{\circ} \mathrm{C}\right)\end{array}$ & $\begin{array}{c}\text { Umidade relativa } \\
\text { média do ar }(\%)\end{array}$ & $\begin{array}{c}\text { Número de } \\
\text { amostras }\end{array}$ \\
\hline $\begin{array}{c}\text { Junho } \\
\mathbf{2 0 0 0}\end{array}$ & 262,2 & 16,0 & 14,7 & 82 & 17 \\
$\begin{array}{c}\text { Setembro } \\
\mathbf{2 0 0 0}\end{array}$ & 242,4 & 16,2 & 15,2 & 79 & 15 \\
$\begin{array}{c}\text { Dezembro } \\
\mathbf{2 0 0 0}\end{array}$ & 154,2 & 23,9 & 22,8 & 72 & 21 \\
$\begin{array}{c}\text { Fevereiro } \\
\mathbf{2 0 0 1}\end{array}$ & 124,8 & 25,7 & 26,3 & 81 & 2 \\
\hline
\end{tabular}

Tabela II - Análise de Correlação Linear de Pearson entre os fatores ambientais (Precipitação, Umidade relativa do ar e temperatura do ar) e o número de indivíduos e amostras coletadas durante os meses de trabalho na UHDF

\begin{tabular}{|c|c|c|c|c|c|c|}
\hline & $\begin{array}{c}\mathrm{N}^{\circ} \text { de } \\
\text { individuos }\end{array}$ & $\begin{array}{c}\mathrm{N}^{\circ} \text { de } \\
\text { amostras }\end{array}$ & Precipitação & $\begin{array}{c}\text { Temperatura } \\
\text { média da } \\
\text { quinzena }\end{array}$ & $\begin{array}{c}\text { Temperatura } \\
\text { média do } \\
\text { mês }\end{array}$ & $\begin{array}{c}\text { Umidade } \\
\text { relativa do } \\
\text { ar }\end{array}$ \\
\hline $\begin{array}{c}\mathrm{N}^{\circ} \text { de } \\
\text { individuos }\end{array}$ & 1,0 & 0,57 & 0,91 & $-0,87$ & $-0,85$ & 0,33 \\
\hline $\begin{array}{c}\mathrm{N}^{\circ} \text { de } \\
\text { amostras }\end{array}$ & 0,57 & 1,0 & 0,49 & $-0,54$ & $-0,45$ & $-0,58$ \\
\hline Precipitação & 0,91 & 0,49 & 1,0 & $-0,99^{*}$ & $-0,99^{*}$ & 0,39 \\
\hline $\begin{array}{l}\text { Temperatura } \\
\text { média da } \\
\text { quinzena }\end{array}$ & $-0,87$ & $-0,54$ & $-0,99^{\star}$ & 1,0 & 0,99 & $-0,30$ \\
\hline $\begin{array}{l}\text { Temperatura } \\
\text { média do mês }\end{array}$ & $-0,85$ & $-0,45$ & $-0,99^{*}$ & 0,99 & 1,0 & $-0,39$ \\
\hline $\begin{array}{l}\text { Umidade } \\
\text { relativa do ar }\end{array}$ & 0,33 & $-0,58$ & 0,39 & $-0,30$ & $-0,39$ & 1,0 \\
\hline
\end{tabular}


Carolina Coelho Sokolowicz

Luciane Ayres Peres

Alunas do Curso de Ciências Biológicas

Universidade Federal de Santa Maria

Santa Maria, RS

SANDRO SANTOS

ssantos@ccne.ufsm.br

Departamento de Biologia - CCNE

Universidade Federal de Santa Maria

Santa Maria, RS - Brasil 